\title{
Finding Wolbachia in Filarial larvae and Culicidae Mosquitoes in Upper Egypt Governorate
}

\author{
Ahmed K. Dyab, Lamia A. Galal, Abeer E. Mahmoud*, Yasser Mokhtar \\ Department of Parasitology, Faculty of Medicine, Assiut University, Assiut, Egypt
}

\begin{abstract}
Wolbachia is an obligatory intracellular endosymbiotic bacterium, present in over $20 \%$ of all insects altering insect reproductive capabilities and in a wide range of filarial worms which is essential for worm survival and reproduction. In Egypt, no available data were found about Wolbachia searching for it in either mosquitoes or filarial worms. Thus, we aimed to identify the possible concurrent presence of Wolbachia within different mosquitoes and filarial parasites, in Assiut Governorate, Egypt using multiplex PCR. Initially, 6 pools were detected positive for Wolbachia by single PCR. The simultaneous detection of Wolbachia and filarial parasites (Wuchereria bancrofti, Dirofilaria immitis, and Dirofilaria repens) by multiplex PCR was spotted in 5 out of 6 pools, with an overall estimated rate of infection (ERI) of $0.24 \%$. Unexpectedly, the highest ERI $(0.53 \%)$ was for Anopheles pharoensis with related Wolbachia and W. bancrofti, followed by Aedes $(0.42 \%)$ and Culex $(0.26 \%)$. We also observed that Wolbachia altered Culex spp. as a primary vector for W. bancrofti to be replaced by Anopheles sp. Wolbachia within filaria-infected mosquitoes in our locality gives a hope to use bacteria as a new control trend simultaneously targeting the vector and filarial parasites.
\end{abstract}

Key words: Wuchereria bancrofti, Dirofilaria immitis, Dirofilaria repens, Wolbachia, filaria, Culicidae, single PCR, multiplex PCR

\section{INTRODUCTION}

Wolbachia is a confusing $\alpha$-proteobacterium, first identified in the ovaries of Culex mosquitoes [1] and is probably the most common known endosymbiotic microbe in the biosphere [2]. Intracellular Wolbachia bacteria are estimated to naturally infect approximately $20 \%$ of insect species and up to $28 \%$ of surveyed mosquito species [3-5]. Naturally occurring Wolbachia has been identified in a range of mosquito species [4-7]. Mosquitoes are infected by "A" and "B" Wolbachia supergroups. Single B super-group strain of Wolbachia was mostly associated with Culex pipiens. The bacteria affect several aspects of insect biology, immunity, ecology, evolution, reproduction including male killing, and parthenogenesis [8]. Cytoplasmic incompatibility (CI) is the most common effect of Wolbachia on mosquitoes, as both infected and uninfected males are reproductively compatible with infected females [9], while uninfected female mosquitoes did not result in fertilization [7]. This phenomenon of $\mathrm{CI}$ gives infected females a reproductive

- Received 6 January 2016, revised 6 May 2016, accepted 7 May 2016.

*Corresponding author (abeerwns@yahoo.com; abeerwnss@gmail.com; abmahmoud@aun.edu.eg)

() 2016, Korean Society for Parasitology and Tropical Medicine

This is an Open Access article distributed under the terms of the Creative Commons Attribution Non-Commercial License (http://creativecommons.org/licenses/by-nc/4.0) which permits unrestricted non-commercial use, distribution, and reproduction in any medium, provided the original work is properly cited. dvantage and allows Wolbachia to drive rapidly through their host [10]. This rapid spread has created an applied interest in the use of this bacterium as a mechanism to drive introduced transgenic traits to spread through wild and naïve mosquito populations to control mosquito-borne diseases [10-13]. Thus identifying naturally occurring Wolbachia in mosquitoes is useful as it is technically easier to transfer transgenic traits between closely related mosquito species [14].

The majority of filarial nematodes, including Dirofilaria immitis, Dirofilaria repens, Onchocerca volvulus, Brugia malayi, and Wuchereria bancrofti harbor the obligate intracellular endosymbiotic bacteria "Wolbachia" [15-17]. The effects of the symbiotic bacteria on parasites of public health importance had been studied and had evidenced the obligatory symbiotic relationship between them and Wolbachia, indicating a long-term and stable association between the 2 organisms [16]. Most, but not all, species of filariae naturally contain Wolbachia of the other 2 groups designated as "C and D" [15], which are required for fertility, molting, development, and survival [8]. Wolbachia is present in all developmental stages of filariae: rapidly increasing as the nematode is introduced from the insect to the mammalian host. It increases further as the larvae develop into adults [18], concentrated within the hypodermal lateral cords of both sexes and transmitted through the egg cytoplasm of the female reproductive organs [19]. This ability of Wolbachia 
to spread rapidly through mosquitoes and to impair the development of their inside pathogens either virus or metazoan makes it a first-rate candidate for reducing disease transmission by vector species, and novel Wolbachia strain for such interventions needs to be carefully considered [20]. Consideration of the mutualistic/symbiotic relationship between the bacteria and their inhabited filariae possibly will sooner or later lead to the discovery of new drug targets.

It is worth to say that lymphatic filariasis is one the most debilitating diseases in tropical medicine [21], in addition to other filarial parasites like $D$. immitis and $D$. repens which are also widely studied due to their zoonotic potential with an increasing number of cases in non-endemic areas [22]. Wolbachia rather than the hosted filarial parasites had been considered as the cause of pathogenesis and inflammatory processes in the course of parasitic infections $[23,24]$. This will allow the development of new therapeutic approaches to filariae $[25,26]$. Accordingly, Wolbachia became a target for filarial nematodes control measures.

Mosquitoes are vectors of filarial nematodes and other vector-transmitted agents, and the current control routine is use of insecticides. However, the presence of mosquito strains resistant with decreased susceptibility has been roused. Likewise, insecticides have negative effects on non-target insect populations, for instance, toxicological effects on humans and environment. Consequently, the implementation of alternative methods to control mosquitoes is needed. Wolbachia-based control is low cost, friendly to the environment, and affects indoors vectors $[8,18]$. It is for that purpose essential to critically assess the incidence of Wolbachia in natural populations of mosquitoes in order to better understand how to introduce novel Wolbachia strains in the process of vector control. As the release, Wolbachia-infected mosquitoes may provide a way to interrupt the transmission cycle of vector-transmitted agents.

As far as we know, there has been no previous study in Upper Egypt conducted to identify the simultaneous presence of naturally infected Wolbachia in mosquitoes, humans, and canine filariasis by multiplex-PCR among the studied localities in Assiut Governorate, Assiut, Egypt.

\section{MATERIALS AND METHODS}

\section{Mosquito collection and DNA extraction}

A total of 2,500 adult engorged female mosquitoes were collected from El-Nikhila, El-Matiaa, Mankabad villages, Sahel
Seleem, El-Badary, Dairout and Manfalout districts, Assiut Governorate, Egypt, throughout 22 months using a mechanical aspirator [27]. Collected mosquitoes were identified [2830]. Female mosquitoes were divided into 100 pools (25 mosquitoes each) according to their genera and collection site. All pool specimens were labeled and maintained refrigerated until being used. Two types of PCR-assays were carried out; firstly single PCR for Wolbachia identification followed by multiplex PCR for simultaneous detection of Wolbachia, W. bancrofti, D. immitis, and $D$. repens within the identified mosquito genera pool from their respective collected sites. All used oligonucleotide primers were a pair of forward and reverse primers obtained from Metabion International AG (Martinsried, Germany). Genomic DNA was isolated from mosquitoes using Qiagen tissue kit (QIAamp DNA Minikit, Hilden, Germany), following the manufacturer's instructions.

\section{Single PCR for Wolbachia detection}

Wolbachia primers used were "Wolbachia $16 \mathrm{~S}$ rDNA, W-Spec forward 5'-CATACCTATTCGAAGGGATAG-3' and W-Spec reverse 5'-AGCTTCGAGTGAAACCAATTC-3' [31].

A Perkin Elmer 480 Thermal Cycler (Perkin Elmer Cetus, Norwalk, Connecticut, USA) was used for the PCR amplification, in $25 \mu \mathrm{l}$ reaction mixtures consisting of $0.5 \mathrm{mM}$ of each primer, $0.6 \mathrm{mM}$ of dNTP, $1 \mathrm{mM} \mathrm{MgCl}_{2}, 1 \mu$ l of the crude DNA extract, $0.2 \mathrm{U}$ of Taq polymerase, $2.5 \mu \mathrm{l}$ of $10 \times$ PCR buffer, and $1 \mu \mathrm{l}$ of DMSO. Each reaction mixture was overlaid with a drop of mineral oil. PCR was performed with initial denaturation at $94^{\circ} \mathrm{C}$ for $2 \mathrm{~min}$, followed by 30 cycles consisting of $94^{\circ} \mathrm{C}$ for 30 sec, $50.7^{\circ} \mathrm{C}$ for $1 \mathrm{~min}$ and $72^{\circ} \mathrm{C}$ for $1 \mathrm{~min}$, and a final extension for $4 \mathrm{~min}$ at $72^{\circ} \mathrm{C}$. Following PCR, $10 \mu \mathrm{l}$ of each PCR product was taken underneath the oil and mixed with $3 \mu \mathrm{l}$ gel loading dye, loaded on a $2 \%$ agarose gel, and subjected to electrophoresis. An electric field (70 V) was applied for $45 \mathrm{~min}$ to remove the negatively charged DNA molecules through the porous gel. DNA fragments were visualized by staining with ethidium bromide. This fluorescent dye intercalates between bases of DNA. Finally, the PCR-generated fragment sizes were visualized when illuminated with ultraviolet light. DNA bands were compared with the molecular weight marker running alongside (100 bp DNA ladder, Promega, Madison, Wisconsin, USA). The gel was destained in tap water (for $15 \mathrm{~min}$ ), then photographed. 
Multiplex PCR for simultaneous detection of Wolbachia and filarial parasites

Positive pools "by single PCR for Wolbachia" were examined by multiplex PCR using Qiagen Multiplex PCR kit (Qiagen) following the manufacturer's instructions.

W. bancrofti primers were ispWb12 forward primer 5'-CTGA GTGAAATCAATGAACTGC-3' and reverse primer pWb12 R 5'GT CCATCCGATGAAGTTCCACC-3' primers [32].

The primers used for D. immitis were the forward DI COI-F1 5'-AGTGTAGAGGGTCAGCCTGAGTTA- $3^{\prime}$ and the reverse DI COI-R1 5'-ACAGGCACTGACAATACCAAT-3'. D. repens primers were the forward Dr ITS2-F (5'-CATTGATAGTTTA-CATTC AAATAA-3') and the reverse Dr ITS2-R (5'-GATTCATTTATTGC ATTA-AGCAAGC-3') [33].

The procedure of multiplex PCR were as follows. The $2 \mathrm{x}$ QIAGEN Multiplex PCR Master Mix, template DNA, RNasefree water, and primer mix were defrosted. The solutions were mixed completely before use. Multiplex PCR components included reaction mix and template DNA. The reaction mix (total volume of $50 \mu \mathrm{l} /$ reaction) was prepared as follows: $25 \mu \mathrm{l} 2 \mathrm{x}$ QIAGEN multiplex PCR Master Mix, $5 \mu \mathrm{l}$ (10x primer mix, 2 $\mu \mathrm{M}$ of each primer) and variable volumes of RNase-free water. The reaction mix was mixed thoroughly and appropriate volumes were dispensed into PCR tubes. The template DNA (1 $\mu \mathrm{g} / 50 \mu \mathrm{l}$ reaction) was added to individual PCR tubes containing the reaction mix. PCR tubes containing the reaction mix were overlaid with approximately $50 \mu \mathrm{l}$ mineral oil. The PCR tubes were placed in the thermal cycler, and the cycling program was programmed according to the manufacturer's instructions using universal multiplex cycling protocol. Detection of multiplex PCR products were detected by agarose gel electrophoresis, followed by staining with $2 \%$ ethidium bromide, and DNA was visualized under ultraviolet illumination compared to 100 bp ladder molecular weight marker (100 bp DNA ladder and negative control (non-blood fed mosquitoes) were obtained from Research Institute of Medical Entomology (Dokki, Egypt) and used in each PCR reaction.

\section{Statistical analysis}

The collected data were analyzed by the program SPSS version 20 for Windows (Chicago, Illinois, USA). The rate of infection in mosquitoes was calculated by the estimated rate of infection (ERI) using the following formula: ERI $=1-(1-\mathrm{X} / \mathrm{m})^{1 / \mathrm{k}}$, where ' $\mathrm{X}$ ' is the number of positive pools; ' $\mathrm{m}$ ' is the number of examined pools, and ' $\mathrm{k}$ ' is the average number of specimens in each pool [34].

\section{RESULTS}

\section{Detection of Wolbachia by single PCR using Wolbachia $16 \mathrm{~S}$ rDNA}

We screened the presence of Wolbachia in 2,500 mosquitoes collected from 7 localities. They, representing 5 species belonging to 3 genera of mosquitoes, were identified as Culex spp. (C. pipiens, C. antennatus, C. pusillus, and grouped as Culex spp. pool), Anopheles pharoensis, and Aedes caspius.

They were divided into 100 pools. Six pools (6\%) were positive for Wolbachia in 4 (57\%) localities, with an overall ERI of $0.24 \%$. The infection status of each locality and the numbers of screened mosquitoes along with ERI were listed in Table 1 and Fig. 1.

Table 1. Localities monitored by single PCR for Wolbachia and number of pools simultanously positive for filaria and Wolbachia by multiplex PCR irrespective to mosquitos' genera, along with the estimated rate of infection (ERI; \%) for both Wolbachia and filarial parasites and their statistical significance

\begin{tabular}{lccc}
\hline Localities & $\begin{array}{c}\text { Infection status by single PCR for Wolbachia } \\
\text { (No. of mosquitoes) }\end{array}$ & $\begin{array}{c}\text { No. of pools positive for Wolbachia and } \\
\text { filariae/tested pools (\%) }\end{array}$ & $\begin{array}{c}\text { ERI (\%) } \\
\text { El-Nikhila }\end{array}$ \\
El-Matiaa & $+(575)$ & $3 / 23(13.0)$ & $0.557^{\mathrm{a}}$ \\
Sahel Seleem & $+(325)$ & $1 / 13(7.7)$ & $0.319^{\mathrm{b}}$ \\
Dairout & $+(350)$ & $1 / 14(7.1)$ & $0.295^{\mathrm{c}}$ \\
El-Badary & $+(350)$ & $1 / 14^{\mathrm{e}}(7.1)$ & $0.295^{\mathrm{d}}$ \\
Mankabad & $-(350)$ & $0 / 14(0)$ & $0^{\mathrm{a}, \mathrm{b}, \mathrm{c}, \mathrm{d}}$ \\
Manfalout & $-(250)$ & $0 / 10(0)$ & $0^{\mathrm{a}, \mathrm{b}, \mathrm{c}, \mathrm{d}}$ \\
Total & $-(300)$ & $0 / 12(0)$ & 0 \\
\hline
\end{tabular}

a-dSame letter means significant difference between them.

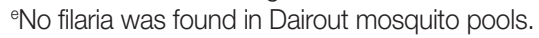




\section{Simultaneous detection of Wolbachia and filariae by multiplex PCR}

Only 64 mosquito pools from the 4 naturally infected Wolbachia localities were screened for simultaneous detection of Wolbachia and filarial parasites (W. bancrofti, D. immitis, and D.

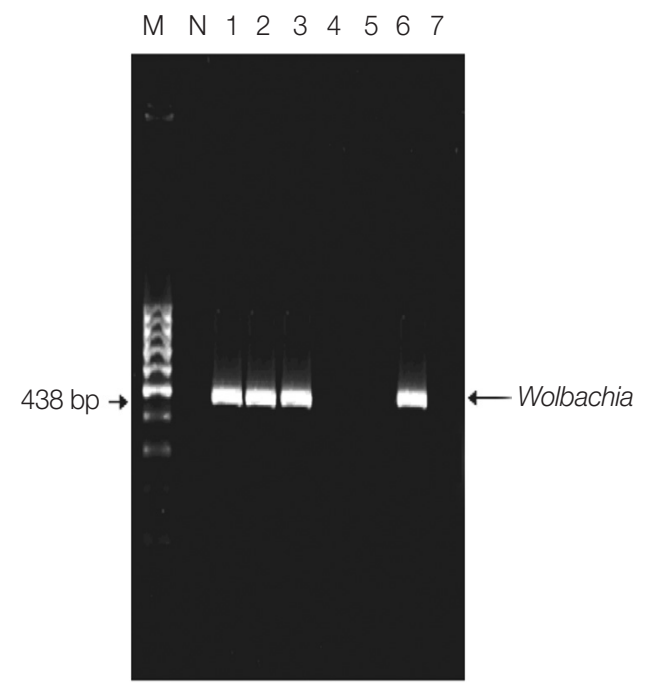

Fig. 1. Detection of Wolbachia endosymbiotic bacterial DNA in pools by single PCR of indoor-resting mosquitoes. Lane 1, El-Nikhila village; lane 2, El-Matiaa village; lane 3, Sahel Seleem city; lane 4, El-Badary city; lane 5, Mankabad village; lane 6, Dairout city; lane 7, Manfalout city. M, 100 bp DNA marker; N, negative control (nonblood fed mosquitoes). Wolbachia detected at $438 \mathrm{bp}$.

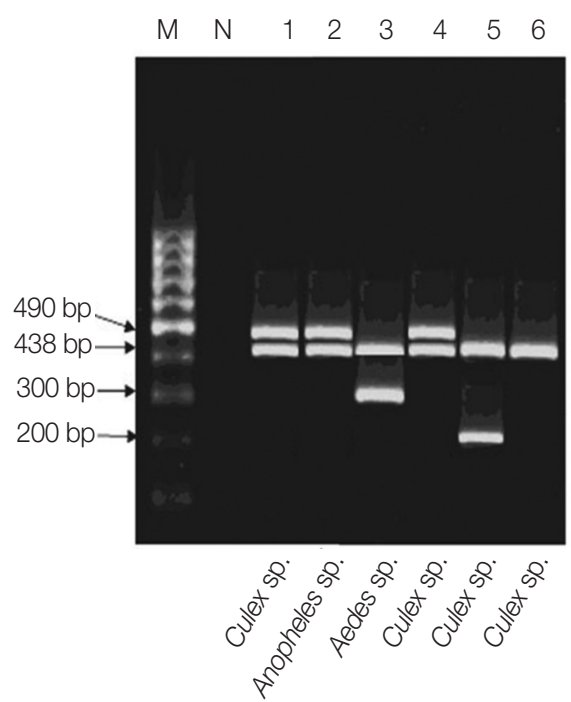

Fig. 2. Multiplex PCR pattern showing association of Wolbachia with filarial parasites within their respective vectors in the studied locality. Lanes 1-3, El-Nikhila village; lane 4, El-Matiaa village; lane 5, Sahel Seleem district; lane 6, Dairout district. Wuchereria bancrofti at $490 \mathrm{bp}$, Wolbachia at $438 \mathrm{bp}$, Dirofilaria repens at 300 bp, and Dirofilaria immitis at $200 \mathrm{bp}$.

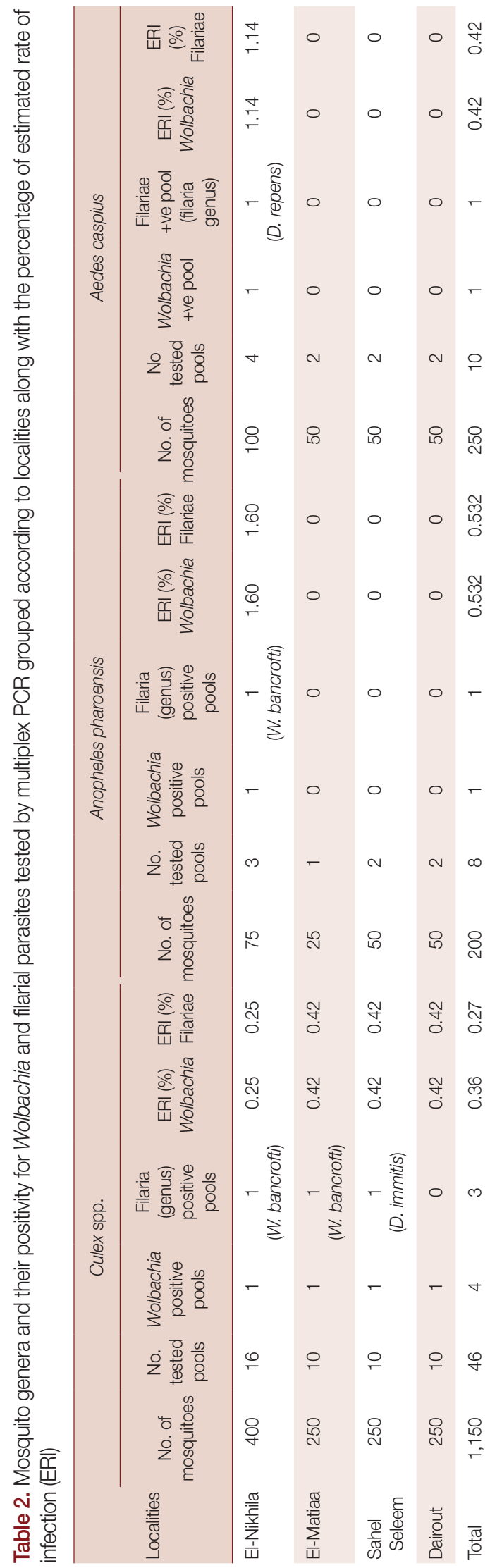


Table 3. Number of mosquito specimens and pools tested according to their genera and their positivity for Wolbachia and filarial parasites along with the percentage of estimated rate of infection (ERI)

\begin{tabular}{|c|c|c|c|c|c|c|}
\hline \multirow{2}{*}{ Mosquito genera } & \multirow{2}{*}{$\begin{array}{l}\text { Total no. of } \\
\text { mosquitoes }\end{array}$} & \multirow{2}{*}{$\begin{array}{l}\text { No. of } \\
\text { tested pools }\end{array}$} & \multirow{2}{*}{$\begin{array}{l}\text { No. of pools positive for } \\
\text { Wolbachia/tested (\%) }\end{array}$} & \multirow{2}{*}{$\begin{array}{l}\text { No. of pools positive for } \\
\text { filaria/tested (\%) }\end{array}$} & \multicolumn{2}{|c|}{ ERI (\%) } \\
\hline & & & & & $\left.E\right|^{a}$ & $\left.E R\right|^{b}$ \\
\hline Culex spp. & 1,150 & 46 & $4(8.7)$ & $3(6.5)$ & 0.363 & 0.269 \\
\hline Aedes caspius & 250 & 10 & $1(10.0)$ & $1(10.0)$ & 0.420 & 0.420 \\
\hline Anopheles pharoensis & 200 & 8 & $1(12.5)$ & $1(10.0)$ & 0.532 & 0.532 \\
\hline Total & 1,600 & 64 & $6 \quad(9.4)$ & $5(7.8)$ & 0.392 & 0.324 \\
\hline
\end{tabular}

ERl ${ }^{a}$ for Wolbachia; ERl ${ }^{b}$ for filaria.

Table 4. The infection status of the studied mosquito genera by multiplex PCR simultaneously holding Wolbachia and filarial parasites

\begin{tabular}{|c|c|c|c|c|c|c|c|c|c|c|c|c|}
\hline & \multicolumn{3}{|c|}{ Culex spp. } & \multicolumn{3}{|c|}{ Anopheles pharoensis } & \multicolumn{3}{|c|}{ Aedes caspius } & \multicolumn{3}{|c|}{$\begin{array}{l}\text { Mosquito pool positive for } \\
\text { Wolbachia and filaria }\end{array}$} \\
\hline & $\begin{array}{l}\text { No. } \\
\text { tested } \\
\text { pools }\end{array}$ & $\begin{array}{l}\text { No. of } \\
\text { positive } \\
\text { pools }\end{array}$ & ERI (\%) & $\begin{array}{l}\text { No. } \\
\text { tested } \\
\text { pools }\end{array}$ & $\begin{array}{l}\text { No. of } \\
\text { positive } \\
\text { pools }\end{array}$ & ERI (\%) & $\begin{array}{l}\text { No. of } \\
\text { tested } \\
\text { pools }\end{array}$ & $\begin{array}{l}\text { No. of } \\
\text { positive } \\
\text { pools }\end{array}$ & ERI (\%) & $\begin{array}{l}\text { No. } \\
\text { tested } \\
\text { pools }\end{array}$ & $\begin{array}{l}\text { No. of } \\
\text { positive } \\
\text { pools }\end{array}$ & ERI (\%) \\
\hline W. bancrofti & 46 & 2 & $0.17^{\mathrm{a}}$ & 3 & 1 & 1.6 & 4 & - & - & 53 & 3 & $0.23^{\mathrm{a}, \mathrm{b}}$ \\
\hline D. repens & 46 & - & - & 3 & - & - & 4 & 1 & & 53 & 1 & $0.07^{\mathrm{a}}$ \\
\hline D. immitis & 46 & 1 & $0.08^{\mathrm{a}}$ & 3 & - & - & 4 & - & - & 53 & 1 & $0.07^{b}$ \\
\hline
\end{tabular}

Only tested pools proved to be positive for Wolbachia were used in this calculation.

a,bSame letter means significant difference between them.

repens) in a single pool by multiplex PCR (Table 2). Only 6 pools (9.3\%) were positive for Wolbachia from which 5 pools (83\%) were associated with filarial parasite within their respective vector. Dairout district was filarial parasites free (Tables 1, 2; Fig. 2). Within the tested 4 localities, the genera most commonly represented was Culex spp. $(\mathrm{n}=1,150 ; 71 \%)$ followed by A. caspius ( $\mathrm{n}=250 ; 15 \%)$ and A. pharoensis $(\mathrm{n}=200$; $12.5 \%$ ) (Table 3). The 3 mosquito genera were enclosing Wolbachia (either within the mosquito itself or the co-infected filarial parasites). Unexpectedly, the overall highest ERI (0.53\%) was for A. pharoensis and co-infected W. bancrofti, followed by Aedes (0.42\%) co-infected by D. repens and Culex sp. (0.36\%) co-infected by either $W$. bancrofti or $D$. immitis (Table 3 ).

El-Nikhila village had the highest mosquito rate of infection (ERI 0.55\%), where the 3 mosquito genera, Wolbachia, and filarial parasites (W. bancrofti and D. repens) as listed in Tables 1, 2, and Fig. 2 and A. pharoensis recorded the highest ERI (1.6\%) equally for Wolbachia and $W$. bancrofti (Table 2). The rate of infection of mosquitoes co-infected with Wolbachia and W. bancrofti was of $0.23 \%$; nevertheless, it is less likely to found mosquitoes simultaneously associating Wolbachia with either $D$. immitis or D. repens as the ERI was $0.07 \%$ (Table 4).

\section{DISCUSSION}

To our knowledge, investigation on the relation between Wolbachia, mosquito genera and filarial parasites in Upper Egypt had not been undertaken so far. For instance, Kassem et al. [35] had studied the relation between Wolbachia and Phlebotomus sp., and the presence of Wolbachia in the Delta region of Egypt had been recorded only within W. bancrofti microfilariae [36]. Therefore, it is important to survey the distribution of this bacterium among the mosquitoes population in a given locality and also the harbored filarial parasites in order to plan any Wolbachia-based control program. We found out, by single PCR, that just in 2 out of the 7 studied localities "ElBadary and Manfalout" and their collected mosquito pools of "Culex, Aedes, and Anopheles genera" were not only free of filarial parasites but also of endosymbiotic Wolbachia. This finding was also reached by Kassem et al. [35] as they failed to detect Wolbachia in 1 out of the 4 colonies of Egyptian sandflies indicating that the inter- and intra-specific spread of Wolbachia is discontinuous, signifying the patchy distribution of the bacteria even within a country. We can even add within the same localities, as Mokhtar [37] had screened his mosquito pools for Wolbachia prior to his study and were free of it.

Culex spp. are the most abundant species collected from the 4 studied localities (72\%) and the most abundant mosquitoes 
in Upper Egypt [37-39]. El-Nikhila, El-Matiaa villages, and Sahel Seleem district were positively infected with both filarial parasite and the endosymbiotic bacteria, excluding Dairout where Wolbachia inhabits the Culex spp. pools; evidencing the invasion to the comprised Culex species (C. pipiens, C. pusillus, and C. antennatus). Osei-Poku [20], from Kenya, found that 26-75\% of the collected Aedes, Culex, and Mansonia genera and $42 \%$ of Culex spp. were infected by Wolbachia likewise in India in which Ravikumar et al. [7] found that $50 \%$ of collected $\mathrm{Cu}$ lex spp. were positive for Wolbachia and were of medical importance. C. pipiens is described to be infected up to $100 \%$ with their respective Wolbachia strains throughout the majority of their geographical ranges $[8,40,41]$. Nonetheless, uninfected C. pipiens population were found in many parts of the world $[42,43]$ coming along with the present results in which C. pipiens as one of the constituents of the Culex pool were free of Wolbachia. This finding needs to be investigated by focusing on each species consisting this pool, C. pusillus, C. antennatus, and specifically $C$. pipiens.

As the used primer is an all strain "Wolbachia 16S rDNA, WSpec", we cannot know where the Wolbachia resides in the mosquito or filarial parasites? Here comes the dilemma, the studied Culex pools had the least ERI $(0.36 \%$ and $0.26 \%$ for Wolbachia and filariae, respectively) in distinction to A. pharoensis with higher ERI $(0.53 \%)$ and A. caspius $(0.42 \%)$ for either Wolbachia or filaria. Despite the fact that Culex spp., including $C$. antennatus and specifically $C$. pipiens, are known to be the primary vector of W. bancrofti in Egypt [44-46] and reported by authors of the same locality $[37,47]$, where Culex spp. had the highest ERI for W. bancrofti followed by Anopheles sp. The current decline of Culex spp. as the primary vector for W. bancrofti could be explained by the presence of Wolbachia either within the parasite or in the vector. If we are assuming that Wolbachia is challenging with the filaria parasite over the vector host; Farid et al. [45] stated that the susceptibility of $\mathrm{Cu}$ lex spp. to W. bancrofti infection could be altered in different mosquitoe species and even among different geographical strains. Wolbachia strains give negative effects by reducing the fitness and shortening the lifespan of their hosts as compared to the uninfected mosquito vectors [18,48-50]. In addition, authors had stated that Wolbachia of filarial nematodes (separate clade) could be horizontally transmitted to their enclosed vectors $[15,16]$, consequently adding to, may be present or not, another load of bacteria affecting the vector fitness which could explain this regression in the vector role of Culex sp. For that reason, A. pharoensis has presently emerged as an alternating vector for $W$. bancrofti, which is known to be a secondary vector for $W$. bancrofti and more focally involved in its transmission $[46,51]$. It has to be taken into consideration that Anopheles sp. are reported to be free of natural Wolbachia infection $[7,8,20]$, and the herein detected Wolbachia infection is with conviction present within the beholden $W$. bancrofti inside which the bacteria flourish, co-infecting the $A$. pharoensis pool. Therefore, rise up the role of $A$. pharoensis as a secondary vector for $W$. bancrofti which seems refractory to the horizontal transmission of Wolbachia and subsequently to the negativity of Wolbachia on the mosquito fitness. The ERI of A. pharoensis to $W$. bancrofti in El-Nikhila village reached $1.6 \%$ in contrast to $0.9 \%$ in the same locality by Dyab et al. [47] where it was proved to be free of Wolbachia.

The co-infection of mosquito vectors with filaria increases the ability to find Wolbachia either in the filarial host or the vector. It may be worth noting that Culex pool was also found to be the vector of D. immitis and co-infected with Wolbachia. Bandi et al. [52] and Pourali et al. [53], used the similar 16S rDNA, W-Spec primer which had proved the Wolbachia presence within D. immitis. A. caspius was found to be co-harbored by $D$. repens and Wolbachia with an ERI of $0.42 \%$. It should be noted that more than 1,000 screened A. caspius in Italy were negative for Wolbachia [5]. Currently, we could not be decisive where does the Wolbachia reside? However, many authors had verified its occurrence within $D$. repens [54]. The evident obligatory symbiotic relationship from several reports on filarial worms was that rendering the bacterial depletion kills adult worms and blocks embryogenesis (microfilariae output) [27]. The susceptibility to antibiotic treatment and the development of the host nematode are slowed or prevented by depletion of Wolbachia [54]. Since we found that the infection status of the studied mosquito genera simultaneously holding Wolbachia and filarial parasites and that $W$. bancrofti had the highest ERI $(0.23 \%)$ followed by the equal ERI $(0.7 \%)$ for $D$. repens and $D$. immitis, the assumed presence of Wolbachia within W. bancrofti and another filarial parasite in our locality should motivate the treatment of patients and control of filariae by the use of specific anti-Wolbachia antibiotic in addition to the usual antifilarial drugs.

In conclusion, our results describes the first molecular detection of Wolbachia endobacteria in different genera of mosquito pools co-infected with filarial parasites captured from endemic filaria localities in Assiut Governorate, Egypt. The presence of 
Wolbachia in co-existing with $W$. bancrofti within the Culex spp. vectors had altered the transmission of lymphatic parasite in favor of the A. pharoensis vector. However, this study is still inadequate and needs further works in order to determine the distribution and genotyping of Wolbachia endobacteria found in our community mosquito vectors co-infected with filarial parasites.

\section{ACKNOWLEDGMENT}

The financial support of this work is from the grant office, Faculty of Medicine, Assiut University, Assiut, Egypt.

\section{CONFLICT OF INTEREST}

We have no conflict of interest related to this work.

\section{REFERENCES}

1. Hertig M, Wolbach SB. Studies on rickettsia-like microorganisms in insects. J Med Res 1924; 44: 329-374.

2. Iturbe-Ormaetxe I, Walker T, O'Neill SL. Wolbachia and the biological control of mosquito-borne disease. EMBO Rep 2011; 12: 508-518.

3. Werren JH, Windsor D, Guo LR. Distribution of Wolbachia among neotropical arthropods. Proc Biol Sci 1995; 262: 197-204.

4. Kittayapong P, Baisley KJ, Baimai V, O’Neill SL. Distribution and diversity of Wolbachia infections in Southeast Asian mosquitoes (Diptera: Culicidae). J Med Entomol 2000; 37: 340-345.

5. Ricci I, Cancrini G, Gabrielli S, D’Amelio S, Favia G. Searching for Wolbachia (Rickettsiales: Rickettsiaceae) in mosquitoes (Diptera: Culicidae): large polymerase chain reaction survey and new identifications. J Med Entomol 2002; 39: 562-567.

6. Rasgon JL, Scott TW. An initial survey for Wolbachia (Rickettsiales: Rickettsiaceae) infection in selected California mosquitoes (Diptera: Culicidae). J Med Entomol 2004; 41: 255-257.

7. Ravikumar H, Ramachandraswamy N, Sampathkumar S, Prakash BM, Huchesh HC, Uday J, Puttaraju HP. A preliminary survey for Wolbachia and bacteriophage WO infections in Indian mosquitoes (Diptera: Culicidae). Trop Biomed 2010; 27: 384393.

8. Bourtzis K, Dobson SL, Xi Z, Rasgon JL, Calvitti M, Moreira LA, Bossin HC, Moretti R, Baton LA, Hughes GL, Mavingui P, Gilles JRL. Harnessing mosquito-Wolbachia symbiosis for vector and disease control. Acta Trop 2014; 132 (suppl): S150-S163.

9. Stouthamer R, Breeuwer JA, Hurst GD. Wolbachia pipientis: microbial manipulator of arthropod reproduction. Annu Rev Microbiol 1999; 53: 71-102.

10. Turelli M, Hoffmann AA. Microbe-induced cytoplasmic incompatibility as a mechanism for introducing transgenes into ar- thropod populations. Insect Mol Biol 1999; 8: 243-255.

11. Pettigrew MM, O’Neill SL. Control of vector-borne disease by genetic manipulation of insect vectors: technological requirements and research priorities. Austral J Entomol 1997; 36: 309-317.

12. Rasgon JL, Scott TW. Wolbachia and cytoplasmic incompatibility in the California Culex pipiens mosquito species complex: parameter estimates and infection dynamics in natural populations. Genetics 2003; 165: 2029-2038.

13. Blagrove MS, Arias-Goeta C, Failloux AB, Sinkins SP. Wolbachia strain wMel induces cytoplasmic incompatibility and blocks dengue transmission in Aedes albopictus. Proc Natl Acad Sci U S A 2012; 109: 255-260.

14. Russell JA, Goldman-Huertas B, Moreau CS, Baldo L, Stahlhut JK, Werren JH, Pierce NE. Specialization and geographic isolation among Wolbachia symbionts from ants and lycaenid butterflies. Evolution 2009; 63: 624-640.

15. Bandi C, Anderson TJ, Genchi C, Blaxter ML. Phylogeny of Wolbachia in filarial nematodes. Proc Biol Sci 1998; 265: 2407-2413.

16. Taylor MJ, Bilo K, Cross HF, Archer JP, Underwood AP. 16S rDNA phylogeny and ultrastructural characterization of Wolbachia intracellular bacteria of the filarial nematodes Brugia malayi, B. pahangi, and Wuchereria bancrofti. Exp Parasitol 1999; 91: 356361.

17. Grandi G, Morchon R, Kramer L, Kartashev V, Simon F. Wolbachia in Dirofilaria repens, an agent causing human subcutaneous dirofilariasis. J Parasitol 2008; 94: 1421-1423.

18. Slatko BE, Luck AN, Dobson SL, Foster JM. Wolbachia endosymbionts and human disease control. Mol Biochem Parasitol 2014; 195: 88-95

19. Taylor MJ. Wolbachia in the inflammatory pathogenesis of human filariasis. Ann N Y Acad Sci 2003; 990: 444-449.

20. Osei-Poku J, Han C, Mbogo CM, Jiggins FM. Identification of Wolbachia strains in mosquito disease vectors. PLoS One 2012; 7: e49922.

21. WHO Progress report 2000-2009 and strategic plan 2010-2020 of the global programme to eliminate lymphatic filariasis: halfway towards eliminating lymphatic filariasis. Geneva, Switzerland. WHO. 2010 (http://whqlibdoc.who.int/publications/2010 /9789241500722_eng.pdf).

22. Latrofa MS, Montarsi F, Ciocchetta S, Annoscia G, Dantas-Torres F, Ravagnan S, Capelli G, Otranto D. Molecular xenomonitoring of Dirofilaria immitis and Dirofilaria repens in mosquitoes from north-eastern Italy by real-time PCR coupled with melting curve analysis. Parasit Vectors 2012; 5: 76-83.

23. Townson S, Tagboto S, McGarry HF, Egerton GL, Taylor MJ. Onchocerca parasites and Wolbachia endosymbionts: evaluation of a spectrum of antibiotic types for activity against Onchocerca gutturosa in vitro. Filaria J 2006; 5: 1-9.

24. Landum M, Ferreira CC, Calado M, Alho AM, Maurício IL, Meireles JS, de Carvalho LM, Cunha C, Belo S. Detection of Wolbachia in Dirofilaria infected dogs in Portugal. Vet Parasitol 2014; 204: 407-410.

25. Lee SF, White VL, Weeks AR, Hoffmann AA, Endersby NM. High- 
throughput PCR assays to monitor Wolbachia infection in the dengue mosquito (Aedes aegypti) and Drosophila simulans. Appl Environ Microbiol 2012; 78: 4740-4743.

26. Taylor MJ, Hoerauf A, Townson S, Slatko BE, Ward SA. Anti-Wolbachia drug discovery and development: safe macrofilaricides for onchocerciasis and lymphatic filariasis. Parasitology 2014; 141: 119-127.

27. Silver JB. Mosquito ecology: field sampling methods. 3rd ed. New York, USA. Springer. 2008.

28. Russell PF, Rozeboom LE, Stone A. Keys to the Anopheline mosquitoes of the world with notes on their identification, distribution, biology, and relation to Malaria. American Entomological Society. 1943, p 1-152.

29. Natvig LR. Contributions to knowledge of the Danish and Fennoscandian mosquitoes-Culicini. Suppl Norsk Entomologisk Tidsskrift. 1948, p 567.

30. Gad AM. Mosquitoes of oasis of the Libyan Desert of Egypt. Bull Soc Entomol Egypt 1963; 40: 131-136.

31. Werren JH, Windsor DM. Wolbachia infection frequencies in insects: evidence of a global equilibrium? Proc Biol Sci 2000; 267: $1277-1285$.

32. Siridewa K, Karunanayake EH, Chandrasekharan NV. Polymerase chain reaction-based technique for the detection of Wuchereria bancrofti in human blood samples, hydrocele fluid and mosquito vectors. Am J Trop Med Hyg 1996; 54: 72-76.

33. Rishniw M, Barr SC, Simpson KW, Frongillo MF, Franz M, Alpizar JL. Discrimination between six species of canine microfilariae by a single polymerase chain reaction. Vet Parasitol 2006; 135: 303-314.

34. Cowling DW, Gardner IA, Johnson WO. Comparison of methods for estimation of individual-level prevalence based on pooled samples. Prev Vet Med 1999; 39: 211-225.

35. Kassem HA, Hassan AN, Abdel-Hamid I, Osman G, El Khalab EM, Madkour MA. Wolbachia infection and the expression of cytoplasmic incompatibility in sandflies (Diptera: Psychodidae) from Egypt. Ann Trop Med Parasitol 2003; 97: 639-644.

36. Rao RU, Atkinson LJ, Ramzy RM, Helmy H, Farid HA, Bockarie MJ, Susapu M, Laney SJ, Williams SA, Weil GJ. A real-time PCRbased assay for detection of Wuchereria bancrofti and in blood and mosquitoes. Am J Trop Med Hyg 2006; 74: 826-832.

37. Mokhtar Y. Parasitological Studies on Mosquitoes as Vectors for Parasitic Diseases with Special Reference to Filariae in Assiut Governorate. M.D. Thesis, Parasitology Department, Faculty of Medicine, Assiut University, Assiut, Egypt. 2014.

38. Khalil GM. A preliminary survey of mosquitoes in Upper Egypt. J Egypt Public Health Assoc 1981; 55: 355-359.

39. El-Nazer MM. Parasitological and immunological studies on filarial worms in Assiut Governorate. Ph.D. thesis, Department of Medical Parasitology, Faculty of Medicine, Assiut University, Assiut, Egypt. 1990.

40. Duron O, Lagnel J, Raymond M, Bourtzis K, Fort P, Weill M. Transposable element polymorphism of Wolbachia in the mos- quito Culex pipiens: evidence of genetic diversity, superinfection, and recombination. Mol Ecol 2005; 14: 1561-1573.

41. Duron O, Raymond M, Weill M. Many compatible Wolbachia strains coexist within natural populations of Culex pipiens mosquito. Heredity 2011; 106: 986-993.

42. Cornel AJ, McAbee RD, Rasgon J, Stanich MA, Scott TW, Coetzee M. Differences in extent of genetic introgression between sympatric Culex pipiens and Culex quinquefasciatus (Diptera: Culicidae) in California and South Africa. J Med Entomol 2003; 40: 36-51.

43. Rasgon JL, Cornel AJ, Scott TW. Evolutionary history of a mosquito endosymbiont revealed through mitochondrial hitchhiking. Proc Biol Sci 2006; 273: 1603-1611.

44. Harb M, Faris R, Gad AM, Hafez ON, Ramzy RM, Buck AA. The resurgence of lymphatic filariasis in the Nile Delta. Bull WHO 1993; 71: 49-54.

45. Farid H, Hammad RE, Kamal SA, Christensen BM. Selection of a strain of Culex pipiens highly susceptible to Wuchereria bancrofti. Egypt J Biol 2000; 2: 125-131.

46. Manguin S, Bangs MJ, Pothikasikorn J, Chareonviriyaphap T. Review on global co-transmission of human Plasmodium species and Wuchereria bancrofti by Anopheles mosquitoes. Infect Genet Evol 2010; 10: 159-177.

47. Dyab AK, Galal LA, Mahmoud AE, Mokhtar Y. Xenomonitoring of different filarial nematodes using single and multiplex PCR in mosquitoes from Assiut Governorate, Egypt. Korean J Parasitol 2015; 53: 77-83.

48. Xi Z, Dean JL, Khoo C, Dobson SL. Generation of a novel Wolbachia infection in Aedes albopictus (Asian tiger mosquito) via embryonic microinjection. Insect Biochem Mol Biol 2005; 35: 903910.

49. Xi Z, Khoo CCH, Dobson SL. Wolbachia establishment and invasion in an Aedes aegypti laboratory population. Science 2005; 310: 326-328.

50. McMeniman CJ, Lane RV, Cass BN, Fong AW, Sidhu M, Wang YF, O'Neill SL. Stable introduction of a life-shortening Wolbachia infection into the mosquito Aedes aegypti. Science 2009; 323: 141144.

51. Ramzy RM. Field application of PCR-based assays for monitoring Wuchereria bancrofti infection in Africa. Ann Trop Med Parasitol 2002; 96(suppl 2): S55-S59.

52. Bandi C, Trees AJ, Brattig NW. Wolbachia in filarial nematodes: evolutionary aspects and implications for the pathogenesis and treatment of filarial diseases. Vet Parasitol 2001; 98: 215-238.

53. Pourali P, Roayaei Ardakani M, Jolodar A, Razi Jalali MH. PCR screening of the Wolbachia in some arthropods and nematodes in Khuzestan province. Iran J Vet Res (Shiraz University) 2009; 10(3 ser. no. 28): 216-222.

54. Simón F, Siles-Lucas M, Morchón R, González-Miguel J, Mella I, Carretón E, Montoya-Alonso JA. Human and animal dirofilariasis: the emergence of a zoonotic mosaic. Clin Microbiol Rev 2012; 25: 507-544. 